\title{
Inhibition of return in a discrimination task
}

\author{
JAY PRATT \\ Washington University, St. Louis, Missouri
}

\begin{abstract}
Inhibition of return (IOR) refers to a bias against returning visual attention to a location that has been recently attended. Although IOR has been demonstrated in a wide range of detection tasks, it has not been reliably shown in discrimination tasks. The results of the present experiment, in which eye movement responses and a cue-target procedure were used, indicate that IOR can exist in a discrimination task. Moreover, the results indicate that the amount of IOR in the discrimination task was approximately equal to that found in the detection task. The results suggest that IOR will be obtained in a discrimination task if the prior allocation of attention does not yield any useful information concerning the forthcoming discrimination judgment.
\end{abstract}

Inhibition of return (IOR) refers to a bias against attending to visual stimuli that are presented at a previously attended location (Posner \& Cohen, 1984). Previous research has shown that drawing attention to a location and then moving attention away from that location sometimes results in attention's being inhibited from returning to the original location (e.g., Maylor \& Hockey, 1985, 1987; Posner \& Cohen, 1984; Tipper, Driver, \& Weaver, 1991). As a result, attention may be moved more rapidly to a novel location than to a previously attended location. This effect has been interpreted as the product of a mechanism that enhances attentional searches by biasing attentional allocation to novel locations and away from previously inspected locations (Posner \& Cohen, 1984; Tipper, Weaver, Jerreat, \& Burak, 1994).

If IOR represents a mechanism for enhancing attentional search, one would expect IOR to be a relatively robust effect. This is true; IOR has been demonstrated in a wide range of experimental paradigms. Longer response latencies have been found for stimuli that have appeared in validly cued static locations (Abrams \& Dobkin, 1994a; Posner \& Cohen, 1984; Rafal, Calabresi, Brennan, \& Sciolto, 1989), validly cued dynamic objects (Abrams \& Dobkin, 1994b; Tipper et al., 1991; Tipper et al., 1994), and validly cued locations on dynamic objects (Gibson \& Egeth, 1994b). Additionally, IOR has been found in simple manual reaction time (RT) detection tasks (Maylor \& Hockey, 1987), choice manual RT detection tasks (Maylor, 1985), and eye movement responses (Abrams \& Dobkin, 1994a, 1994b; Vaughan, 1984). However, most

This research was supported by Grant R29-MH45145 from the National Institutes of Health to R. A. Abrams. The author would like to thank R. A. Abrams, Mark B. Law, Heather Oonk, and Alison L. Chasteen for their helpful comments. The author would also like to thank Tram Neill, James Neely, and one anonymous reviewer for greatly improving this manuscript. Correspondence concerning this article should be sent to J. Pratt, Department of Psychology, Campus Box 1125 , Washington University, St. Louis, MO 63130 (e-mail: jpratt@artsci. wustl.edu). of these studies required subjects to make responses involving the detection of a single target stimulus presented at either a validly cued or an invalidly cued location.

Recently, Terry, Valdes, and Neill (1994) presented three experiments which suggest that IOR does not occur when subjects are required to make discrimination, not detection, responses (see also Neill, Terry, \& Valdes, 1994). In explicitly testing for IOR in a discrimination task, Terry et al. (1994) used two possible target stimuli and two possible nontarget stimuli. Their results suggested that IOR was not present when a target/nontarget discrimination was required.

Terry et al. (1994) used two basic paradigms in examining IOR in discrimination tasks. One paradigm involved the presentation of either a target or a nontarget stimulus to the right or left of fixation. Subjects were required to make a simple manual response to the appearance of only a target stimulus (Experiment 1) or to make a choice manual RT response to the appearance of a target or a nontarget stimulus (Experiment 3 ). The other paradigm used by Terry et al. (1994, Experiment 2 ) involved the simultaneous presentation of both the target and the nontarget stimuli (on opposite sides of fixation) with a choice manual RT response to only the location of the target stimulus. In all three of these experiments, Terry et al. employed a "target-target" procedure, in which subjects responded to each presentation of the stimuli. They consistently found inhibition when repeated targets occurred at the same position in nondiscrimination (i.e., detection) conditions but facilitation when repeated targets occurred at the same position in the discrimination conditions. Because IOR was not found in their discrimination tasks, Terry et al. suggest that IOR may not represent a general attentional phenomenon.

There is, however, some evidence to suggest that IOR may exist in some discrimination tasks that do not involve discriminations based on object identity. Posner, Rafal, Choate, and Vaughan (1985) presented subjects with a single peripheral cue (to the right or left of fixation), then a center fixation cue, and then two peripheral 
targets (to the left and right of fixation). Subjects were instructed to move their eyes in whichever direction was more comfortable or natural. Subjects were more likely to move their eyes to the target location opposite that of the location of the cue, suggesting that IOR was present. A similar finding was reported by Clohessy, Posner, Rothart, and Vecera (1991), who tested infants. In a recent study, Gibson and Egeth (1994a) found evidence for IOR in a temporal order judgment task. Subjects were presented with a single peripheral cue (to the left or right of fixation). Following the cue, the first peripheral target (T1) was presented to either the left or the right of fixation. After a variable target-asynchrony delay, the second peripheral target (T2) was presented at the peripheral location opposite that of T1. Subjects were instructed to determine, as quickly as possible, in which location T1 occurred. Gibson and Egeth (1994a) found evidence for IOR in such a discrimination task, although the effect was modulated by the size of the targetasynchrony delay. Thus, as Terry et al. (1994) point out, there may be conditions under which IOR does occur in a discrimination task.

The goal of the present experiment was to further investigate IOR in a discrimination task by using a paradigm that has previously produced strong IOR effects in detection tasks (Abrams \& Dobkin, 1994a, 1994b; Pratt \& Abrams, in press). In the present experiment, attention was cued to either the right or the left of fixation by the brief onset of a single asterisk. Then, in the discrimination task, two stimuli (a box and a diamond, one of which was designated as a target) were simultaneously presented to the right and left of fixation. In the detection task, only a single target stimulus (a box or a diamond) was presented. In both tasks, subjects were required to make eye movement responses to the location of the designated target stimulus.

\section{METHOD}

\section{Subjects}

Sixteen subjects from Washington University, divided into two groups of 8 subjects each, participated in a single 1-h long session. All the subjects had normal, uncorrected vision and were naive with regard to the purpose of the experiment. They were paid \$6 for participating.

\section{Apparatus and Procedure}

The experiment was conducted in a dimly illuminated, soundproof booth. The subjects were seated directly in front of a computer monitor, with their heads held steady by a chin/headrest. They wore a spectacle frame fitted with a scleral-reflectance eye movement monitor (Applied Science Laboratories, Model 210).

The trial sequence is shown in Figure 1. At the start of each trial, a plus sign was displayed on the monitor directly in front of the subject ( $0^{\circ}$ of visual angle) for $300 \mathrm{msec}$. The plus sign was then replaced by a dot, which the subjects were required to fixate for $800 \mathrm{msec}$. A peripheral cue was then presented either $5^{\circ}$ to the left or right of the fixation dot. The cue was an asterisk that appeared on the monitor for $300 \mathrm{msec}$. Two hundred milliseconds after the removal of the cue, another asterisk was presented at fixation for $300 \mathrm{msec}$. For half the subjects (discrimination task), $160 \mathrm{msec}$ after that cue was removed, the target was presented $5^{\circ}$ to the right or left of fixation and the distractor was presented $5^{\circ}$ from fixation on the side opposite that of the target. Thus, on all trials in the discrimination task, the target and dis-

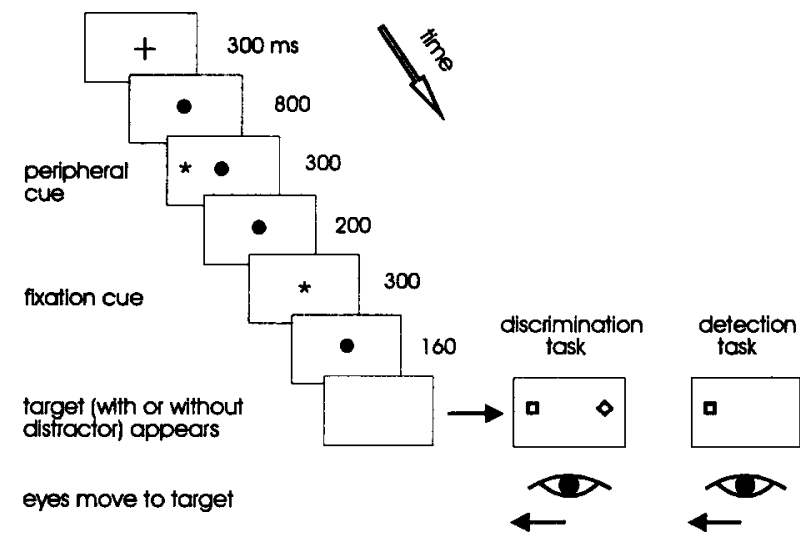

Figure 1. The timing of the trial sequence used in the experiment. The peripheral cue could appear to the left or right of fixation, as could the target (with the distractor always appearing in the opposite location in the discrimination task and never appearing in the detection task). See the text for details.

tractor appeared simultaneously on opposite sides of fixation. For the other half of the subjects (detection task), only the target was presented to the left or right of fixation. All the subjects were instructed to stare at the fixation dot until the presentation of the target/nontarget stimuli, at which point they were to look to the target as quickly and accurately as possible.

\section{Eye Movement Monitoring}

Samples of eye position were digitized and recorded at $1000 \mathrm{~Hz}$. The eye movement monitor was calibrated at the beginning of each session, and the calibration was checked at the beginning of each trial. The subject's eye position was monitored at two points during the trial (after the offset of the peripheral cue and after the offset of the fixation cue) to ensure that his/her eyes did not leave the fixation dot until the target/distractor stimuli were presented. If the subject's eye position was more than $3^{\circ}$ from the fixation dot at either of these two monitoring points, the trial was rejected as an improper fixation.

\section{Design}

The session consisted of seven blocks of 40 trials each. Two objects served as targets and distractors, a square and a diamond. Four subjects from each of the discrimination and detection tasks had the square as the target and the diamond as the distractor, while the other 4 subjects from each task had the diamond as the target and the square as the distractor. In validly cued trials, the cue and the target occurred on the same side of fixation. In invalidly cued trials, the cue and the target occurred on opposite sides of fixation. Half the trials in each block involved validly cued trials and half involved invalidly cued trials. Cues and targets were equally likely to appear to the left or to the right of fixation and were randomly presented throughout the experiment.

\section{RESULTS}

The mean RTs for the errorless trials are shown in Figure 2. The mean RTs were analyzed with a 2 (task: discrimination and detection) $\times 2$ (cuing: validly cued or invalidly cued) $\times 2$ (target location: left or right) analysis of variance (ANOVA). There was a reliable main effect of task $\left[F(1,14)=10.73, M S_{\mathrm{e}}=6,269.19, p<.01\right]$ due to longer RTs in the discrimination task $(274 \mathrm{msec})$ than in the detection task $(209 \mathrm{msec})$. A main effect of cuing $\left[F(1,14)=31.33, M S_{\mathrm{e}}=23.50, p<.0005\right]$ was also found, indicating that responses to the validly cued 


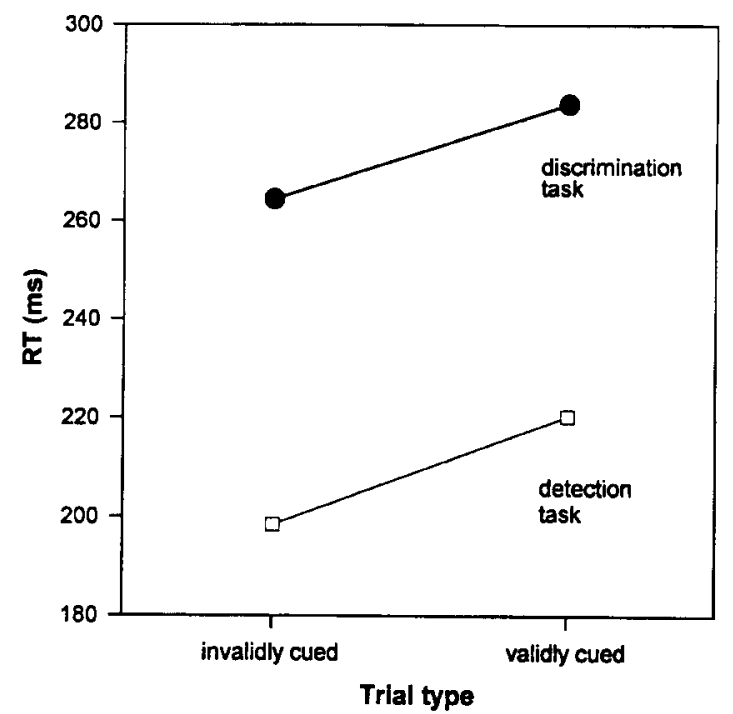

Figure 2. Mean reaction times (RTs) from the errorless trials for the discrimination task (filled circles) and the detection task (open squares).

locations $(252 \mathrm{msec})$ were slower than those to the invalidly cued locations $(231 \mathrm{msec})$ for both tasks. Importantly, no task $\times$ cuing interaction was found $[F(1,14)<$ 1]. Neither the task $\times$ target $[F(1,14)=2.0]$ nor the task $\times$ cuing $\times$ target $[F(1,14)=1.1]$ interaction was reliable.

A similar 2 (task) $\times 2$ (cuing) $\times 2$ (target location) ANOVA was also performed on the percentage of correct responses. These data appear in Table 1. A reliable main effect of task was found $\left[F(1,14)=26.82, M S_{\mathrm{e}}=\right.$ $64.99, p<.0005]$, indicating that fewer correct responses were made in the discrimination task. No other main effect $[F(1,14)<1]$ or interactions $[F \mathrm{~s}(1,14)<2.5, p \mathrm{~s}>.1]$ were reliable.

In order to examine IOR in each of the discrimination and detection tasks further, separate 2 (cuing: validly cued or invalidly cued) $\times 2$ (target location: left or right) ANOVAs were conducted. For the discrimination task, there was a reliable main effect of cuing $[F(1,7)=9.32$, $\left.M S_{\mathrm{e}}=323.78, p<.02\right]:$ responses to targets in the validly cued locations were $19 \mathrm{msec}$ slower than responses to targets in invalidly cued locations. No reliable main effect of target location $[F(1,7)=2.2]$ or interaction $[F(1,7)<1]$ was found. The percentage of correct responses was also analyzed with a 2 (cuing) $\times 2$ (target location) ANOVA. No reliable main effects of cuing

Table 1

Percentage of Correct Responses

\begin{tabular}{cc}
\hline Task & $\%$ \\
\hline Discrimination & \\
Validly cued & 79 \\
Invalidly cued & 80 \\
Detection & \\
Validly cued & 95 \\
Invalidly cued & 94 \\
\hline
\end{tabular}

$[F(1,7)=1.1]$ or target $[F(1,7)=1.3]$ were found, nor was the interaction reliable $[F(1,7)<1]$.

For the detection task, there was a reliable main effect of cuing $\left[F(1,7)=34.30, M S_{\mathrm{e}}=111.39, p<.001\right]$ : responses to targets in the validly cued locations were $22 \mathrm{msec}$ slower than responses to targets in the invalidly cued locations. No reliable effect of target location was found $[F(1,7)<1]$, nor was there an interaction $[F(1,7)<$ 1]. The number of correct responses was also analyzed with a 2 (cuing) $\times 2$ (target location) ANOVA. There were no reliable main effects of cuing $[F(1,7)<1]$ or target $[F(1,7)=1.7]$, nor was there a reliable interaction $[F(1,7)<1]$.

Overall, the results of the present experiment clearly indicate that IOR did occur in the discrimination task. Subjects were slower to respond to the target stimulus when it occurred in the validly cued location whether or not a distractor stimulus was present in the other location. In addition, the lack of a task $\times$ cuing interaction indicates that the effect sizes of IOR found in the discrimination and detection tasks were not different. Further support suggesting that the pattern of responses between the two tasks was similar stems from the lack of a task $\times$ cuing interaction regarding the percentage of correct responses. Thus, the present findings suggest that IOR is not limited to detection tasks only.

\section{DISCUSSION}

Robust IOR effects were found in the discrimination task. Terry et al. (1994) conducted three discrimination experiments, using a different method, and failed to find evidence for IOR. What differences in method might account for such divergent results?

One difference in method was that Terry et al. (1994) used a targettarget procedure (similar to that of Maylor \& Hockey, 1985), whereas a cue-target procedure (similar to that of Posner \& Cohen, 1984) was used in the present study. In Terry et al.'s target-target procedure, only target stimuli are used and the subjects are required to respond to every stimulus: the data are analyzed in terms of the current target location and the location of the immediately preceding target. If the prior allocation of attention to a location has yielded useful information (as in a target for a response), there may be no utility for inhibiting further discrimination responses to that location. As Terry et al. note, if useful information is acquired at a given location, it would seem "unadaptive" to inhibit returning attention to such a location.

In contrast, the present cue-target procedure involves the presentation of a cue and a target on each trial. The subjects are required not to respond to the cue stimulus and only to respond to the target stimulus. Thus, the subjects must inhibit responding to the presentation of the cue. As I have described, the data are analyzed in terms of the current target location and the location of the immediately preceding cue. It may be that because the prior allocation of attention does not yield useful information (subjects did not respond to the cue, nor was the cue involved in a discrimination judgment), a mechanism that biases attending to novel locations would be useful. Thus, in the context of discriminating between stimuli, the target-target and cue-target procedures may have very different consequences for IOR.

Related to the use of the cue-target procedure, the inhibitory effects found in the present experiment may have been due to response inhibition rather than IOR. Subjects were required to inhibit eye movements to the location of the cue, but then make eye movements to the location of the target stimulus. It is possible that inhibiting eye movements to the cued location biases subjects against the production of future eye movements to the same location. Given the intimate relationship between the oculomotor and skeletal motor systems (see, e.g., 
Abrams, Meyer, \& Kornblum, 1990; Bekkering, Adam, Kingma, Huson, \& Whiting, 1994), such response inhibition would also be expected when manual responses are used. However, response inhibition cannot be the whole story. Evidence relevant to this claim comes from Rafal et al. (1989), who found IOR when subjects made different responses to the cue and target (i.e., a saccade to the location of the cue and a keypress response to the location of the target). Thus, it is unlikely that the inhibitory effects found in the present experiment were due only to response inhibition.

Another difference in method between the present experiment and the Terry et al. (1994) study occurred in the type of response that the subjects were required to make. Terry et al. had subjects make manual keypress responses (simple keypress in Experiment 1 and choice keypress in Experiments 2 and 3), whereas in the present experiment subjects made eye movement responses. Given the close relationship between the eye movement system and the attentional orienting system (see, e.g., Shepard, Findlay, \& Hockey, 1986), it may be that the eye movement responses in the present experiment were more sensitive to IOR effects than the manual keypress responses in Terry et al.'s experiment. However, many other researchers have found IOR with manual keypress responses (e.g., Posner \& Cohen, 1984; Rafal et al., 1989; Maylor \& Hockey, 1987). The divergent patterns of results found between the discrimination and detection conditions of Terry et al. also suggest that the lack of IOR effects found in their discrimination conditions was not simply due to the type of response that they used.

Overall, it appears that the most likely candidate to account for the differences in results between the present experiment and the Terry et al. (1994) study was the manner in which attention was allocated to the previously attended location (the target-target vs. cue-target procedures). When useful information regarding a response is obtained at the previously attended location, IOR may not be present when the consequent discrimination judgment is to be made. However, if no useful information is obtained at the previously attended location, then IOR may be present when the consequent judgment is to be made. This explanation is consistent with the notion that IOR represents some sor of adaptive mechanism. If information regarding a discrimination judgment was found at a given location, it would be advantageous not to inhibit returning attention to that location in order to make another discrimination judgment. On the other hand, if an attended location offered no information, it would be advantageous to inhibit returning attention to that location. In detection tasks, where the abrupt onset of the cue captures attention and does not provide any other useful information, it would be advantageous to bias the orienting of attention to novel locations and not to resample locations where no useful information was obtained (Terry et al., 1994). Thus, the nature of the task (detection vs. discrimination) and the informativeness of the prior allocation of attention in relation to the task (target-target vs. cue-target) appear to modulate IOR.

\section{REFERENCES}

Abrams, R. A., \& Dobxin, R. S. (1994a). The gap effect and inhibition of return: Interactive effects on eye movement latencies. Experimental Brain Research, 98, 483-487.

Aвrams, R. A., \& Dobkin, R. S. (1994b). Inhibition of return: Effects of attentional cuing on eye movement latencies. Journal of Experimental Psychology: Human Perception \& Performance, 20, 467477.

Abrams, R. A., Meyer, D. E., \& Kornblum, S. (1990). Eye-hand coordination: Oculomotor control in rapid aimed limb movements.
Journal of Experimental Psychology: Human Perception \& Performance, 16, 248-267.

Bekkering, H., Adam, J. J., Kingma, H., Huson, A., \& Whiting, H. T. A. (1994). Reaction time latencies of eye and hand movements in single- and dual-task conditions. Experimental Brain Research, 97, 471-476.

Clohessy, A. B., Posner, M. I., Rothart, M. K., \& Vecera, S. P. (1991). The development of inhibition of return in early infancy. Journal of Cognitive Neuroscience, 3, 345-350.

GIBSON, B. S., \& EGETH, H. (1994a). Inhibition and disinhibition of return: Evidence from temporal order judgments. Perception \& Psychophysics, 56, 669-680.

GIBSON, B. S., \& EGETH, H. (1994b). Inhibition of return to objectbased and environment-based locations. Perception \& Psychophysics, 55, 323-339.

MAYLOR, E. (1985). Facilitatory and inhibitory components of orienting in visual space. In M. I. Posner \& B. B. Marin (Eds.), Attention and performance XI (pp. 189-204). Hillsdale NJ: Erlbaum.

MAYLOR, E., \& HOCKEY, R. (1985). Inhibitory component of externally controlled covert orienting in visual space. Journal of Experimental Psychology: Human Perception \& Performance, 11, 777-787.

MAYLOR, E., \& HoCKEY, R. (1987). Effects of repetition on the facilitatory and inhibitory components of orienting in visual space. Neuropsychologia, 25, 41-54.

NeILl, W. T., TerRY, K. M., \& VAldes, L. A. (1994). Negative priming without probe selection. Psychonomic Bulletin \& Review, 1, 119-121.

POSNER, M. I., \& COHEN, Y. (1984). Components of visual orienting. In H. Bouma \& D. G. Bouwhuis (Eds.), Attention and performance $X$ (pp. 531-556). Hillsdale NJ: Erlbaum.

Posner, M. I., Rafal, R. D., Choate, L. S., \& Vaughan, J. (1985). Inhibition of return: Neural basis and function. Cognitive Neuropsychology, 2, 211-228.

PratT, J., \& Abrams, R. A. (in press). Inhibition of return to successively cued spatial locations. Journal of Experimental Psychology: Human Perception \& Performance.

Rafal, R. D., Calabresi, P. A., Brennan, C. W., \& Sciolto, T. K. (1989). Saccade preparation inhibits reorienting to recently attended locations. Journal of Experimental Psychology: Human Perception \& Performance, 15, 673-685.

ShePard, M., FindLaY, J. M., \& Hockey, R. J. (1986). The relationship between eye movements and spatial attention. Quarterly Journal of Experimental Psychology, 38A, 475-491.

Terry, K. M., Valdes, L. A., \& NeILl, W. T. (1994). Does "inhibition of return" occur in discrimination tasks? Perception \& Psychophysics, 55, 323-339.

TiPPER, S. P., Driver, J., \& Weaver, B. (1991). Object-centered inhibition of return of visual attention. Quarterly Journal of Experimental Psychology, 43A, 289-298.

TiPPER, S. P., WEAVER, B., JeRreat, L. M., \& BURAK, A. L. (1994). Object- and environment-based inhibition of return of visual attention. Journal of Experimental Psychology: Human Perception \& Performance, 20, 478-499.

VAUGHAN, J. (1984). Saccades directed at previously attended locations in space. In A. G. Gale \& F. Johnson (Eds.), Theoretical and applied aspects of eye movement research (pp. 143-150). Amsterdam: North-Holland.

(Manuscript received May 23, 1994; revision accepted for publication August 24, 1994.) 